\title{
Tailoring microstructure and phase segregation for low friction carbon-based nanocomposite coatings
}

\author{
Shengguo Zhou, ${ }^{a c}$ Liping Wang, ${ }^{* a}$ Zhibin Lu, $^{a}$ Qi Ding, ${ }^{a}$ S. C. Wang, ${ }^{b}$ Robert J. K. Wood ${ }^{b}$ and Qunji Xue ${ }^{a}$ \\ Received 25th October 2011, Accepted 1st June 2012 \\ DOI: 10.1039/c2jm30918a
}

Friction has a direct relation with the energy efficiency and environmental cleanliness in all moving mechanical systems. To develop low friction coatings is extremely beneficial for preserving not only our limited energy resources but also the earth's environment. This study proposes a new design for low friction carbon-based nanocomposite coatings by tailoring the microstructure and phase segregation, and thereby it contributes to better controlling the mechanical and tribological properties.

Experimental findings and theoretical calculations reveal that high-hardness (18.2 GPa), high-adhesion strength $(28 \mathrm{~N})$ as well as low-internal stress $(-0.8 \mathrm{GPa})$ can be achieved by a nanocrystallite/ amorphous microstructure architecture for the nc-WC/a-C(Al) carbon-based nanocomposite coating; in particular low friction $(\sim 0.05)$ can be acquired by creating a strong thermodynamic driving force to promote phase segregation of graphitic carbon from the a-C structure so as to form a low shear strength graphitic tribo-layer on the friction contact surfaces. This design concept is general and has been successfully employed to fabricate a wide class of low friction carbon-based nanocomposite coatings.

\section{Introduction}

Diamond-like carbon (DLC) protective coatings have attracted considerable research attention and have already found themselves in a whole range of engineering applications because of their excellent properties such as high hardness, wear resistance and low friction when sliding against most engineering materials. ${ }^{1-10}$ However, their limitations are low toughness and high internal stress levels. ${ }^{11-13}$ Thus, the design and development of high hardness, high wear resistance, low friction, good toughness and low internal stress level coatings, which will result in a significant increase in the lifetime of mechanical components, are of most importance in fundamental research and industrial applications. Fortunately, the nanocomposite protective coatings can offer a great opportunity to develop such properties, where the hard and soft phases are often mixed so as to get a combination of good mechanical and tribological properties. For example, the mixture of various phases at the nano-scale might achieve synergic effects to improve hardness or toughness. ${ }^{14-17}$ Carbon-based nanocomposite coatings, where the nanocrystalline phase is embedded into an a-C matrix, are considered a new class of protective materials. Hitherto, a type of the most studied

${ }^{a}$ State Key Laboratory of Solid Lubrication, Lanzhou Institute of Chemical Physics, Chinese Academy of Sciences, Lanzhou 730000, PR China. E-mail: lpwang@licp.cas.cn; Fax: +86931 4968163; Tel: +869314968080 ${ }^{b}$ National Centre for Advanced Tribology at Southampton (nCATS), School of Engineering Sciences, University of Southampton, SO17 1BJ, $U K$

'Graduate University of Chinese Academy of Sciences, Beijing 100039, PR China carbon-based nanocomposite can be fabricated by the doping of strong-carbide-forming (SCF) metal such as W, Ti or $\mathrm{Cr}$ and so on, where the metal can bond strongly with carbon to form carbide nanocrystallites in the a-C matrix. ${ }^{18-21}$ For instance, W-doped carbon-based nanocomposite coatings, which formed WC carbide phase in the a-C matrix, have been widely investigated in recent years. Moreover, the hardness, toughness, friction and wear-resistance of these coatings can be tuned to a certain extent by changing the composition and thereby the microstructure of the coatings. ${ }^{22-26}$

Recently, another kind of carbon-based coating involving the doping of weak-carbide-forming (WCF) metal $\mathrm{Al}$, i.e. just bonding weakly or having almost no bonding with carbon, is attracting great attention of the researchers. Most interesting is that these coatings can achieve good toughness and low internal stress coupled with low friction, and these performances were mainly attributed to the Al metal having good ductility and uniformly dissolving into the a-C matrix. However, it would inevitably cost some hardness of the coatings due to its softness. ${ }^{27-31}$ Besides, Wilhelmsson et al. ${ }^{32}$ reported that the soft metal $\mathrm{Al}$, which formed a substitutional solid solution at the $\mathrm{Ti}$ sites in cubic TiC coating, created a situation of a driving force for carbon phase separation from the carbide particles. Unfortunately, they didn't consider a study on the placing of a solid solution of this WCF Al into the DLC matrix. Our previous works found that the addition of such WCF Al metal may facilitate the formation of amorphous carbon during the growth of the coating. Also, the solid solution of $\mathrm{WCF} \mathrm{Al}$ into the a-C matrix can provide a strong thermodynamic driving force to promote graphitic carbon phase segregation on the contact 
surface of the coating induced by elevated temperature during sliding friction. ${ }^{33,34}$ In this paper, this situation of phase segregation of graphitic carbon will be further validated by theoretical calculations.

Consequently, an approach is proposed to design and fabricate carbon-based nanocomposite coatings with improved mechanical and tribological properties, i.e. constructing a nanocrystallite/amorphous microstructure and creating a strong thermodynamic driving force to promote graphitic carbon phase segregation by co-incorporating the SCF W and WCF Al into the a-C matrix. It is found that the microstructure and phase segregation synergic effects can contribute to obtain high-hardness, high-wear resistance and low-friction coupled with goodtoughness and low-internal stress levels for the nc-WC/a-C(Al) carbon-based nanocomposite coating compared to other a-C, a$\mathrm{C}(\mathrm{Al})$ and nc-WC/a-C carbon-based coatings. The experimental findings and theoretical calculations reported in this paper provide a new concept to design and fabricate low friction coatings regarding the microstructure and the chemical states of carbon as well as the correlative phase segregation, and thereby it contributes to better controlling the mechanical and tribological properties of coatings. In particular, this design concept is general and has been successfully employed to fabricate a wide class of low friction carbon-based nanocomposite coatings.

\section{Experimental}

\subsection{Coatings preparation}

Four kinds of a-C, a-C(Al), nc-WC/a-C and nc-WC/a-C(Al) carbon-based coatings were deposited on silicon $\mathrm{p}(100)$ wafer substrates using magnetron sputtering of $\mathrm{W}, \mathrm{Al}$ and graphite (C) targets of $99.99 \%, 99.99 \%$ and $99.80 \%$ purity in an argon gas atmosphere. Prior to deposition, the silicon wafer substrates were first ultrasonically cleaned in acetone and alcohol for $30 \mathrm{~min}$ and then put into the depositing chamber. The base pressure of the depositing chamber was pumped down to $1.0 \times 10^{-3} \mathrm{~Pa}$, then the chamber was backfilled with Ar gas of $100 \mathrm{sccm}$ flow rate to 0.8 $\mathrm{Pa}$. The substrates were cleaned using $\mathrm{Ar}^{+}$bombardment for 30 min at a substrate bias voltage of $-1000 \mathrm{~V}$ to remove some adhering impurities on the substrates. Prior to the coating deposition, a Si interlayer of about $400 \mathrm{~nm}$ thick was deposited by sputtering of Si target ( $300 \mathrm{~W}$ of R.F. power supply, $-300 \mathrm{~V}$ bias voltage and $50 \%$ duty cycle) so as to improve the adhesion of the final coating to the substrate. Subsequently, the carbon-based nanocomposite coatings were deposited under Ar gas of flow rate of $120 \mathrm{sccm}$. In the depositing, the pulse power supply was kept with $40 \mathrm{kHz}$ frequency, $-300 \mathrm{~V}$ bias voltage and $50 \%$ duty cycle, the D.C. power density of the graphite target was kept constant at $6.5 \mathrm{~W} \mathrm{~cm}^{-2}$ and the D.C. power density of the metallic targets was varied for desirable composition. Detailed deposition parameters were described in Table 1. Besides, the depositing parameters were kept same as that of the nc-WC/a-C(Al) carbonbased coating, and then a series of carbon-based nanocomposite coatings were also fabricated including the nc-TiC/a-C(Al), nc$\mathrm{VC} / \mathrm{a}-\mathrm{C}(\mathrm{Al}), \mathrm{nc}-\mathrm{CrC} / \mathrm{a}-\mathrm{C}(\mathrm{Al}), \mathrm{nc}-\mathrm{ZrC} / \mathrm{a}-\mathrm{C}(\mathrm{Al}), \mathrm{nc}-\mathrm{NbC} / \mathrm{a}-\mathrm{C}(\mathrm{Al})$, nc-MoC/a-C(Al), nc-HfC/a-C(Al) and nc-TaC/a-C(Al) protective coatings. During the whole deposition, there was no extraheating to the substrates.

\subsection{Coatings characterization}

The thickness of the as-fabricated carbon-based coatings was measured using a surface profilometre. X-ray photoelectron spectroscopy (XPS) was carried out on a PerkinElmer PHI-5702 multi-functional photoelectron spectrometer with $\mathrm{Al} \mathrm{K} \alpha$ radiation to investigate the compositions and chemical states of carbon in the coatings. Further investigation on the structure of the as-fabricated coatings was performed on a HR800 microRaman spectroscopy instrument using an $532 \mathrm{~nm} \mathrm{Ar}^{+}$laser with a resolution of $1 \mathrm{~cm}^{-1}$. X-ray diffraction (XRD) with a grazing angle of $1^{\circ}$ was performed on a D/Max-2400X diffractometer (Rigaku Co., Japan) with $\mathrm{Cu} \mathrm{K} \alpha$ radiation applied for phase identification and qualitative texture characterization. Further investigations on the microstructure characterization were performed by high-resolution transmission electron microscopy (HRTEM) using JEOL 3010 TEM operated at $300 \mathrm{kV}$. The nanohardness was measured by a Nanotest600 nanoindenter apparatus (MicroMaterials Ltd.) using a Berkovich diamond tip and the indentation depth was about $10 \%$ of the coating thickness to minimize the substrate contribution, and the internal stress was measured by the stress induced bending on an interferometric surface profiler. The curvature radii of the substrate before and after the film deposition were measured by the observation of Newton's rings using an optical interferometer system, and then the internal stress was calculated by the Stoney equation. The scratch test was used to evaluate the adhesion strength on a scratch tester using a diamond indenter of $400 \mu \mathrm{m}$ in radius by continuously increasing the normal load by $100 \mathrm{~N}$ $\mathrm{min}^{-1}$. The load at which the friction force assumed a sharp increase was defined as the critical load $\left(L_{\mathrm{c}}\right)$ of the coating and used as a quasi-quantitative criterion to evaluate the adhesion strength of the coatings on the substrate.

The friction and wear behaviors of the carbon-based coatings were tested by a ball-on-disc reciprocating sliding tribometer in ambient atmosphere with a relative humidity of $35 \pm 5 \%$ under dry sliding conditions. The steel ball with a diameter of $5 \mathrm{~mm}$ was used as the counter body, and all frictional tests were performed under normal load of $5 \mathrm{~N}$, reciprocating amplitude of $5 \mathrm{~mm}$,

Table 1 Deposition parameters of as-fabricated a-C, a-C(Al), nc-WC/a-C and nc-WC/a-C(Al) coatings

\begin{tabular}{llllll}
\hline Coatings & $\begin{array}{l}\text { Deposition pressure } \\
(\mathrm{Pa})\end{array}$ & $\begin{array}{l}\text { Bias voltage } \\
(\mathrm{V})\end{array}$ & $\begin{array}{l}\text { Duty cycle } \\
(\%)\end{array}$ & $\begin{array}{l}\text { Thickness } \\
(\mu \mathrm{m})\end{array}$ & $\begin{array}{l}\text { Deposition rate } \\
\left(\mathrm{nm} \mathrm{min}^{-1}\right)\end{array}$ \\
\hline a-C & 0.8 & -300 & 50 & 1.87 & 20.8 \\
a-C(Al) & 0.8 & -300 & 50 & 2.93 & 2.08 \\
nc-WC/a-C & 0.8 & -300 & 50 & 2.11 & 23.1 \\
nc-WC/a-C(Al) & 0.8 & -300 & 50 & \\
\hline
\end{tabular}


reciprocating frequency of $5 \mathrm{~Hz}$ (line speed of $0.05 \mathrm{~m} \mathrm{~s}^{-1}$ ) and test time of $60 \mathrm{~min}$ (cycles of 18000 ). Subsequently, the wear tracks and wear scars formed on the counter body were characterized by scanning electron microscopy (SEM) and XPS. Besides, the transverse cross-section of wear track for the nc-WC/a-C(Al) carbon-based coating was observed by HRTEM and the sample was prepared using a dual-beam focused ion beam (FIB) technique.

\section{Results and discussion}

\subsection{Chemical composition and microstructure}

The chemical composition of the as-fabricated four kinds of a-C, a-C(Al), nc-WC/a-C and nc-WC/a-C(Al) carbon-based coatings is calculated from the XPS signals corresponding to $\mathrm{C}(1 \mathrm{~s}), \mathrm{W}(4 \mathrm{f})$ and $\mathrm{Al}(2 \mathrm{p})$ core levels using the standard atomic sensitivity factors of the instrument, and is tabulated in Table 2. The composition of the a-C coating is determined to be 100 at. $\% \mathrm{C}$, the a-C(Al) coating is determined to be about 8.3 at. $\% \mathrm{Al}$ and 91.7 at. $\% \mathrm{C}$, the nc-WC/a-C coating is determined to be about 24.1 at. $\% \mathrm{~W}$ and 75.9 at. $\% \mathrm{C}$, and the nc-WC/a-C(Al) coating is determined to be about 16.9 at. $\% \mathrm{~W}, 8.5$ at. $\% \mathrm{Al}$ and 74.6 at. $\% \mathrm{C}$. Subsequently, the XPS offers a further analysis to the structure and bonding state of the coatings because each element has a unique set of binding energies. Furthermore, the $\mathrm{C} 1 \mathrm{~s}$ spectrum in the XPS analysis is mostly used to identify the chemical states of the amorphous carbon. Fig. 1(a) shows the XPS C1s spectra of the as-fabricated a-C, a-C(Al), nc-WC/a-C and nc-WC/a-C(Al) coatings. For the a-C coating, the XPS spectra show only the $\mathrm{C} 1 \mathrm{~s}$ peak at $284.3 \mathrm{eV}$ originating from amorphous carbon. Similarly, the XPS spectra also show only the C1s peak at $284.3 \mathrm{eV}$ originating from amorphous carbon while the intensity of the peak becomes weak for the a-C(Al) coating. It is found that the XPS $\mathrm{C} 1 \mathrm{~s}$ spectra of the WC/a-C carbon-based nanocomposite coating presents an obvious difference to that of the above a-C and a$\mathrm{C}(\mathrm{Al})$ coatings due to its chemical shift at $283.0 \mathrm{eV}$ as in WC. For the $\mathrm{C} 1 \mathrm{~s}$ spectra of the nc-WC/a-C(Al) coating, it shows a small difference with that of the nc-WC/a-C coating. Subsequently, the $\mathrm{C} 1 \mathrm{~s}$ spectra of nc-WC/a-C(Al) is fitted with four components at the binding energies $283.0 \mathrm{eV}, 284.2 \mathrm{eV}, 285.2 \mathrm{eV}$ and $286.5 \mathrm{eV}$ corresponding to $\mathrm{W}-\mathrm{C}$ bonds in the $\mathrm{WC}_{1-X}$ phase, $\mathrm{sp}^{2}$ carbon bonds, $\mathrm{sp}^{3}$ carbon bonds and $\mathrm{C}-\mathrm{O}$ bonds, respectively. Besides, the XPS W(4f) spectra also prove that the metallic tungsten doped in the a-C matrix forms the carbide. However, the peak position of the XPS A12p spectra shown in Fig. 1(b) is at about $72.4 \mathrm{eV}$ measured after further $\mathrm{Ar}^{+}$bombardment to remove the metallic aluminum oxide due to the easily formed metallic oxide
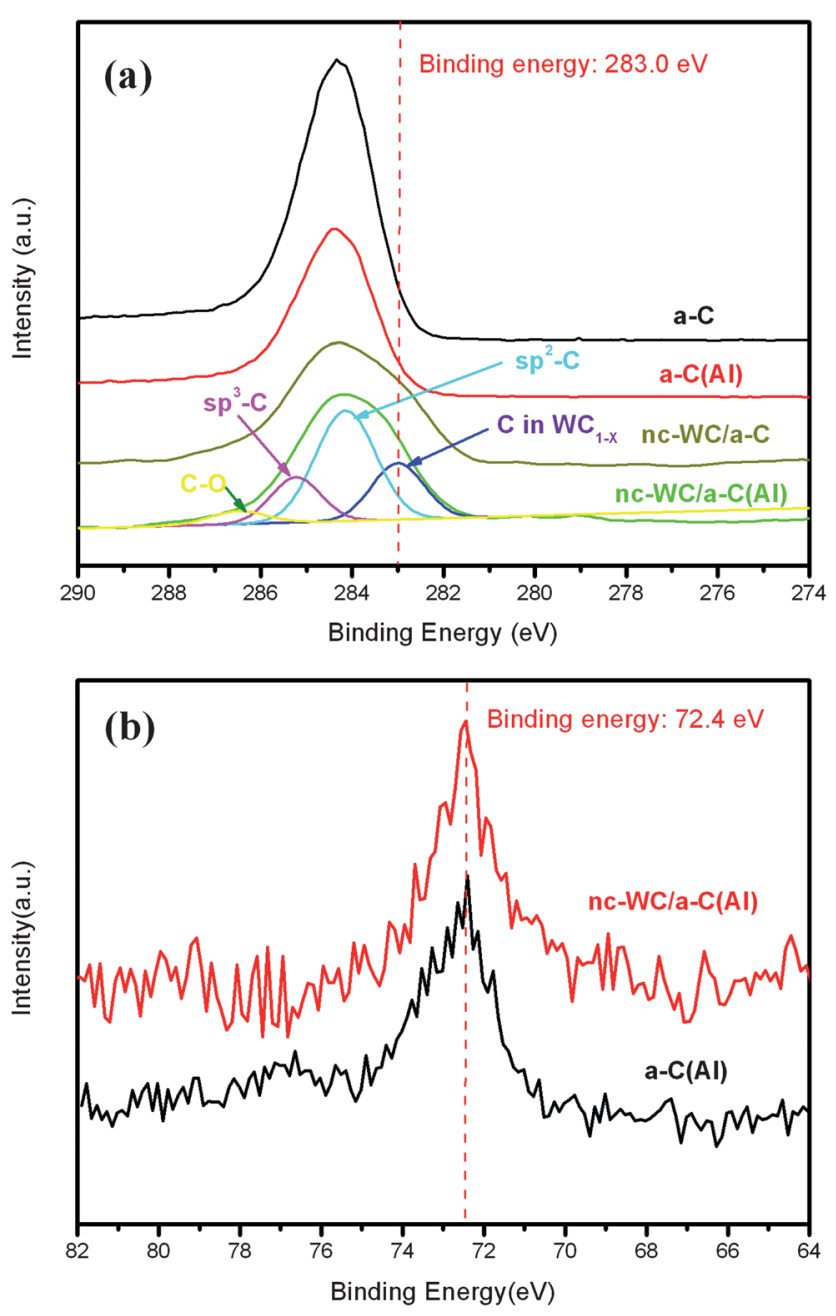

Fig. 1 XPS spectra of as-fabricated carbon-based coatings: (a) XPS C1s and (b) XPS Al2p spectra.

by exposure to air. Besides, as seen in Fig. 1(a), the peak shapes have no noticeable difference between the two XPS C1s spectra of the a-C and a-C(Al) carbon-based coatings. It indicates that aluminum does not form carbide while it uniformly goes into the a-C matrix and thereby exists in the form of a solid solution. These results are well consistent with other reports and our group's previous works. ${ }^{30,31,33,34}$ Furthermore, Raman spectra were acquired from the as-fabricated carbon-based coatings, as shown in Fig. 2. Obviously, the intensities of the D peaks increase gradually for the as-fabricated a-C, a-C(Al), nc-WC/a-C and nc$\mathrm{WC} / \mathrm{a}-\mathrm{C}(\mathrm{Al})$ coatings, indicating a gradual increment in the

Table 2 Chemical composition and mechanical properties of as-fabricated a-C, a-C(Al), nc-WC/a-C and nc-WC/a-C(Al) coatings

\begin{tabular}{|c|c|c|c|c|c|c|c|c|}
\hline \multirow[b]{2}{*}{ Coatings } & \multicolumn{3}{|c|}{$\begin{array}{l}\text { Chemical composition } \\
\text { (at.\%) }\end{array}$} & \multirow[b]{2}{*}{ Hardness (GPa) } & \multirow[b]{2}{*}{$\begin{array}{l}\text { Elastic modulus } \\
(\mathrm{GPa})\end{array}$} & \multirow[b]{2}{*}{$\begin{array}{l}H / E \\
\text { ratio }\end{array}$} & \multirow[b]{2}{*}{$\begin{array}{l}\text { Critical load } \\
(\mathrm{N})\end{array}$} & \multirow[b]{2}{*}{$\begin{array}{l}\text { Residual stress } \\
(\mathrm{GPa})\end{array}$} \\
\hline & $\mathrm{C}$ & W & $\mathrm{Al}$ & & & & & \\
\hline $\mathrm{a}-\mathrm{C}$ & 100 & 0.0 & 0.0 & 17.1 & 223.1 & 0.077 & 13 & -2.9 \\
\hline $\mathrm{a}-\mathrm{C}(\mathrm{Al})$ & 91.7 & 0.0 & 8.3 & 14.8 & 189.5 & 0.078 & 16 & -0.6 \\
\hline nc-WC/a-C & 75.9 & 24.1 & 0.0 & 23.7 & 280.9 & 0.084 & 17 & -2.3 \\
\hline nc-WC/a-C(Al) & 74.6 & 16.9 & 8.5 & 18.2 & 213.2 & 0.085 & 28 & -0.8 \\
\hline
\end{tabular}




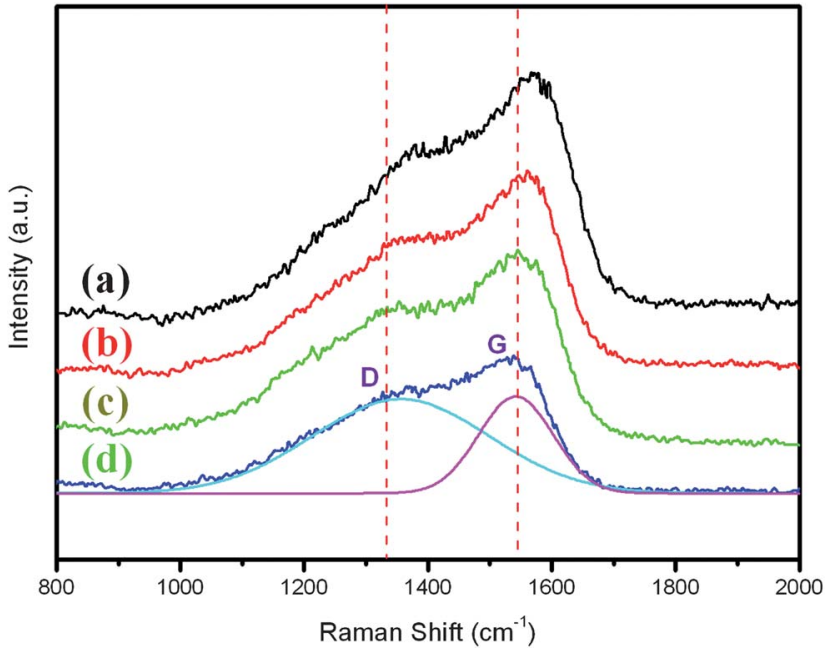

Fig. 2 Raman spectra of as-fabricated carbon-based coatings: (a) a-C, (b) a-C(Al), (c) nc-WC/a-C and (d) nc-WC/a-C(Al).

fraction of $\mathrm{sp}^{2}$ hybridized carbon. Also, the $\mathrm{sp}^{3} / \mathrm{sp}^{2}$ content was determined by the $\mathrm{sp}^{3}$ peak area to $\mathrm{sp}^{2}+\mathrm{sp}^{3}$ peak area in the fitted XPS C1s spectra confirming the results of the Raman spectra, which is about $42 \%, 35 \%, 30 \%$ and $27 \%$ corresponding to the a-C, a-C(Al), nc-WC/a-C and nc-WC/a-C(Al) carbonbased coatings, respectively.

Fig. 3 shows the HRTEM microstructure and selected area electron diffraction (SAED) patterns of the as-fabricated a-C, a$\mathrm{C}(\mathrm{Al})$, nc-WC/a-C and nc-WC/a-C(Al) coatings. HRTEM images (Fig. $3 \mathrm{a}$ and $\mathrm{b}$ ) reveal that both the $\mathrm{a}-\mathrm{C}$ and $\mathrm{a}-\mathrm{C}(\mathrm{Al})$ carbon-based coatings possess typical amorphous characteristics, and the SAED patterns further prove their amorphous microstructure. So it can be concluded that the metallic Al
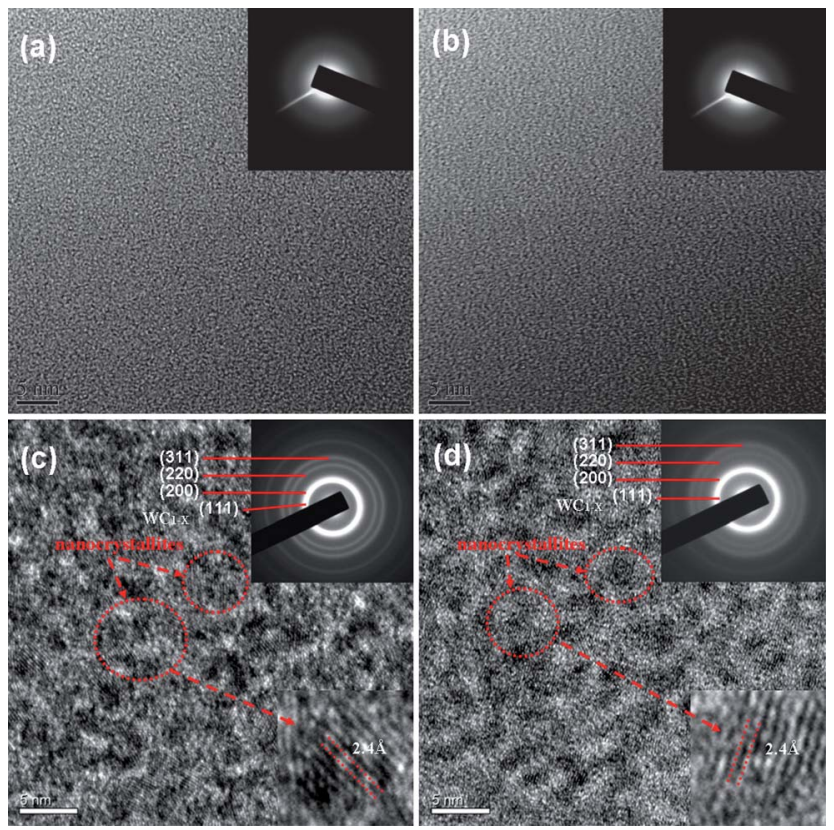

Fig. 3 HRTEM bright-field images and SAED patterns: (a) a-C, (b) a$\mathrm{C}(\mathrm{Al})$, (c) nc-WC/a-C and (d) nc-WC/a-C(Al) coatings. dissolves into the a-C matrix so that the as-fabricated a-C(Al) carbon-based coating is dominated by the typical amorphous structure, which is consistent with the above XPS C1s and Al2p analyses. However, the HRTEM bright-field images (Fig. 3c and d) reveal that both the nc-WC/a-C and nc-WC/a-C(Al) nanocomposite carbon-based coatings have typical nanocrystallite/ amorphous microstructure where the $\mathrm{WC}_{1-X}$ nanoparticles (which mostly are fringed) are uniformly embedded in the amorphous carbon matrix. Herein, Fig. 4 presents the HRTEM bright-field images with different magnification for the nc-WC/a$\mathrm{C}(\mathrm{Al})$ coating, which further confirms its uniformly nanocrystallite/amorphous microstructure. Besides, it can be seen that their corresponding size of grains is about $2-4$ and $1-3 \mathrm{~nm}$, respectively, which also is in good agreement with the results by XRD tests. And, their SAED patterns display four sharp rings with calculated lattice spacings of $2.4,2.1,1.5$ and $1.3 \AA$, and these lattice spacings correspond to the (111), (200), (220) and (311) plane of cubic $\beta-\mathrm{WC}_{1-X}$, respectively. The rings instead of spots confirm the random orientation of the $\beta-\mathrm{WC}_{1-X}$ crystallites in the coatings. The diffraction rings in the simplex W-doped nc-WC/a-C coating (Fig. 3c) are sharper than those in the duplex doped nc-WC/a-C(Al) coating (Fig. 3d). This change shows that the crystal size and crystallinity of the $\mathrm{WC}_{1-X}$ particles decrease with the co-introduction of metallic Al. This is because the sharper diffraction rings indicate that an increased number of carbide particles of high crystallinity exist in the simplex Wdoped nc-WC/a-C coating compared to the nc-WC/a-C(Al) coating. Moreover, from the HRTEM images, the spacings between the nanograins can be estimated. The intergrain spacings are about 3-5 nm and 4-7 nm for the nc-WC/a-C and ncWC/a-C(Al) carbon-based coatings, respectively. Since the size of the crystallites is less than $4 \mathrm{~nm}$ for the nc-WC/a-C(Al) coating, so the intergranular spacing for the nc-WC/a-C(Al) carbon-based coating is large enough to facilitate grain boundary
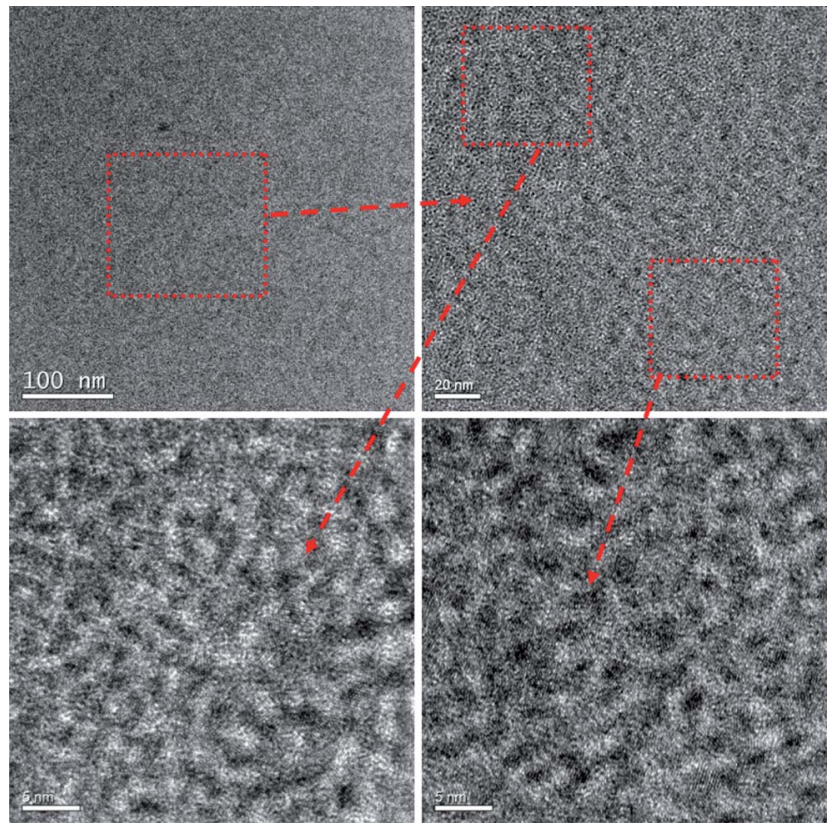

Fig. 4 HRTEM bright-field images with different magnification for ncWC/a-C(Al) coating. 
sliding, indicating a good plasticity might be obtained in this coating. Besides, the surface morphologies of the as-fabricated carbon-based coatings were characterized by an SPM-9500 (Nano IIIa) atomic force microscope (AFM), exhibiting that the nc-WC/a-C(Al) carbon-based coating is relatively uniform and smooth, and their calculated root mean square (RMS) roughnesses were about $0.11,0.15,0.43$ and $0.20 \mathrm{~nm}$ corresponding to the a-C, a-C(Al), nc-WC/a-C and nc-WC/a-C(Al) carbon-based coatings, respectively.

\subsection{Mechanical and tribological properties}

The mechanical properties of the carbon-based coatings are strongly affected by the introduction of metallic Al and W. The main results for the hardness $(H)$, elastic modulus $(E), H / E$ ratio, critical load $\left(L_{\mathrm{c}}\right)$ and residual stress $(\sigma)$ of the as-fabricated a-C, a-C(Al), nc-WC/a-C and nc-WC/a-C(Al) coatings are tabulated in Table 2. It can be seen that the hardness decreases from $\sim 17.1$ $\mathrm{GPa}$ for the a-C coating to $\sim 14.8 \mathrm{GPa}$ with the introduction of $\mathrm{Al}$ metal in the a-C matrix meanwhile the Young's modulus also decreased from $\sim 223.1 \mathrm{GPa}$ to $\sim 189.5 \mathrm{GPa}$. However, both the a-C and a-C $(\mathrm{Al})$ coatings almost occupy the same value of the $H / E$ ratio of about 0.077 . In addition, it can be seen that the hardness apparently increases from $\sim 17.1 \mathrm{GPa}$ for the a-C coating to $\sim 23.7 \mathrm{GPa}$ with the introduction of $\mathrm{W}$ metal in the a$\mathrm{C}$ matrix meanwhile the Young's modulus also increases from $\sim 223.1 \mathrm{GPa}$ to $\sim 280.9 \mathrm{GPa}$. For the $\mathrm{W}$ and $\mathrm{Al}$ co-doped nc-WC/ a-C(Al) nanocomposite coating, it can be seen that both the hardness and Young's modulus keep a relatively high value (hardness of 18.2 GPa and Young's modulus of 213.2 GPa). In particular, its $H / E$ ratio, which is a more suitable parameter for predicting wear resistance, keeps almost the same value (0.085) compared with that of the nc-WC/a-C coating. ${ }^{35-37}$ Besides, by applying the Stoney equation the compressive stress is calculated for the as-fabricated a-C, a-C(Al), nc-WC/a-C and nc-WC/a$\mathrm{C}(\mathrm{Al})$ carbon-based coatings, respectively. It was noticeable that the introduction of $\mathrm{Al}$ metal could achieve a drastic reduction in internal stress while the $\mathrm{W}$ metal just has a small influence on the internal stress. In pure a-C, the internal stress is $-2.9 \mathrm{GPa}$. With doping $\mathrm{Al}$ into a-C, the internal stress experiences an apparent decrease to $-0.6 \mathrm{GPa}$ for the a-C(Al) coating. However, with doping $\mathrm{W}$ into the pure a-C to form the nc-WC/a-C coating, the internal stress presents no pronounced decrease. Remarkably, W and $\mathrm{Al}$ co-doped nc-WC/a-C(Al) just possesses a very low internal stress of $-0.8 \mathrm{GPa}$. For the nc-WC/a-C(Al) carbonbased coating of $\sim 2.1 \mu \mathrm{m}$ in thickness, $-0.8 \mathrm{GPa}$ of internal stress is very low when comparing with hard coatings such as $\mathrm{TiN}, \mathrm{ZrN}$, and HfN, which could easily have an internal stress of several GPa. ${ }^{38,39}$ Moreover, the adhesion strength of four kinds of carbon-based coatings is also evaluated by the scratch tests. The results show that the doping of $\mathrm{W}$ and $\mathrm{Al}$ in the a-C matrix can apparently increase the critical load of the coating. For the pure a-C coating it just has critical load of $\sim 13 \mathrm{~N}$, while the critical load $\left(L_{\mathrm{c}}\right)$ can reach $\sim 28 \mathrm{~N}$ for the nc-WC/a-C(Al) coating. Besides, as seen in the SEM mages of scratch and wear tracks, the nc-WC/a-C(Al) coating presents just some microcracks and less abruptly localized brittle delamination characteristics. Considering the above mechanical results, it can be concluded that the nc-WC/a-C(Al) coating can achieve a superior combination of mechanical properties compared with that of the other a-C, a-C(Al) and nc-WC/a-C carbon-based coatings.

A ball-on-disk tribometer has been used to systematically evaluate the tribological properties of the as-fabricated a-C, a$\mathrm{C}(\mathrm{Al})$, nc-WC/a-C and nc-WC/a-C(Al) coatings under a load of 5 $\mathrm{N}$ with the amplitude of $5 \mathrm{~mm}$ and reciprocating sliding frequency of $5 \mathrm{~Hz}$. Fig. 5 shows the evolution of the friction coefficient versus sliding time. It can be seen that the friction coefficient has a relatively high value of $\sim 0.12$ for the pure a-C coating. When doping $\mathrm{Al}$ in the a-C coating the friction coefficient decreases to a relatively low value of $\sim 0.07$, and doping $\mathrm{W}$ does not have an apparent influence on the friction coefficient (friction coefficient is also $\sim 0.12$ for the nc-WC/a-C coating). However, the friction coefficient decreases to a very low value of about $\sim 0.05$ for the nc-WC/a-C(Al) coating by co-doping $\mathrm{W}$ and Al metals. Considering the above friction results, it can be found that doping $\mathrm{Al}$ in the a-C coating can cause the friction coefficient to decrease to a relatively low value. Previous studies on the tribological behaviors of DLC films confirmed that the low friction coefficient could be attributed to graphitization induced by localized rising temperature at the asperity contacts. ${ }^{40,41}$ Similarly, the formation ability of a low shear strength graphitic interlayer (transfer layer) between the counter body and the coating should play a very important role for the coating with a low friction coefficient. ${ }^{42}$ Therefore, it can be concluded that doping with $\mathrm{Al}$ has an enhanced effect to facilitate the formation of a low shear strength graphitic interlayer under the sliding friction. Besides, the wear rates of four kinds of carbon-based coatings are also calculated, as shown in the inset of Fig. 5. It can be seen that co-doping of $\mathrm{Al}$ and $\mathrm{W}$ metals in the a-C matrix to fabricate the nc-WC/a-C(Al) results in a very low wear rate which is just $\sim 1.8 \times 10^{-16} \mathrm{~m}^{3} \mathrm{~N}^{-1} \mathrm{~m}$. However, the a-C, a-C(Al) and ncWC/a-C coatings have relatively high wear rate such that the wear rate can reach about $8.5 \times 10^{-16} \mathrm{~m}^{3} \mathrm{~N}^{-1} \mathrm{~m}$ for the a-C coating. These results reveal that the nc-WC/a-C(Al) carbonbased coating can possess a high anti-wear property compared to other a-C, a-C(Al) and nc-WC/a-C coatings. Therefore, it can be found that the $\mathrm{W}$ and $\mathrm{Al}$ co-doped nc-WC/a-C(Al) carbon-based

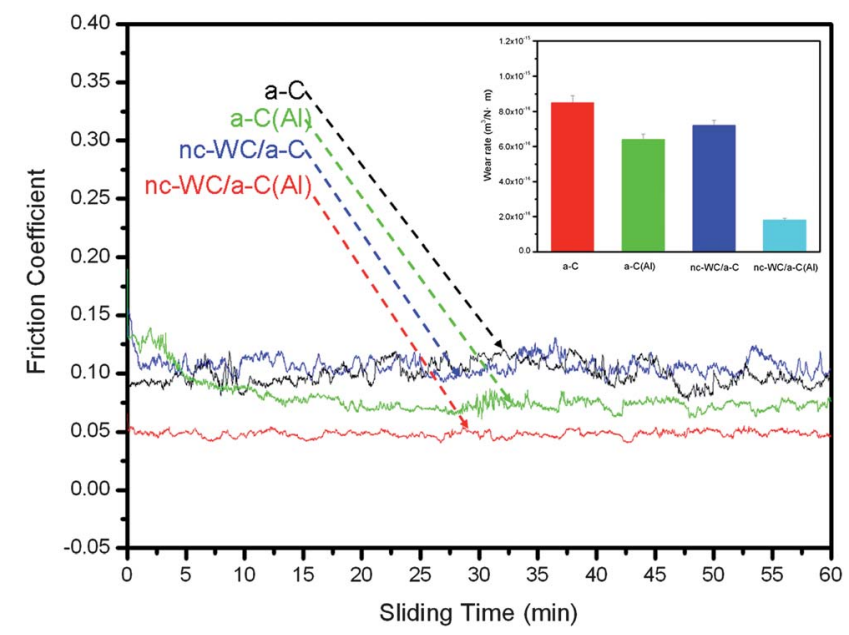

Fig. 5 Friction coefficient and wear rate of as-fabricated a-C, a-C(Al), nc-WC/a-C and nc-WC/a-C(Al) coatings under dry friction. 
nanocomposite coating can achieve superior friction and wear behaviors.

\subsection{Frictional contact surface characteristic}

The wear tracks and wear scars on the counter body are characterized by SEM. Fig. 6a-d show the SEM images of wear tracks and wear scars for the a-C, a-C(Al), nc-WC/a-C and nc-WC/a-C(Al) carbon-based coatings. The SEM images show severely damaged wear tracks and some delaminations for the pure a-C and simplex W-doped nc-WC/a-C coatings whereas the wear is somewhat improved or reduced for the Aldoped a-C(Al) coating. In particular, it can be seen that slight wear and a rather smooth wear surface are characterized for the nc-WC/a-C(Al) coating. Besides, the SEM images show that just a very small part of the wear mark is covered with a transferred film on the steel balls sliding against the a-C and ncWC/a-C coatings. Also, the SEM image shows that the wear mark is covered with a relatively large transferred film whereas the relatively large transferred material is not very continuous and is compacted on the steel ball sliding against the a-C(Al) coating. The noticeable characteristics can be seen in the SEM image of the wear scar on the counter body sliding against the

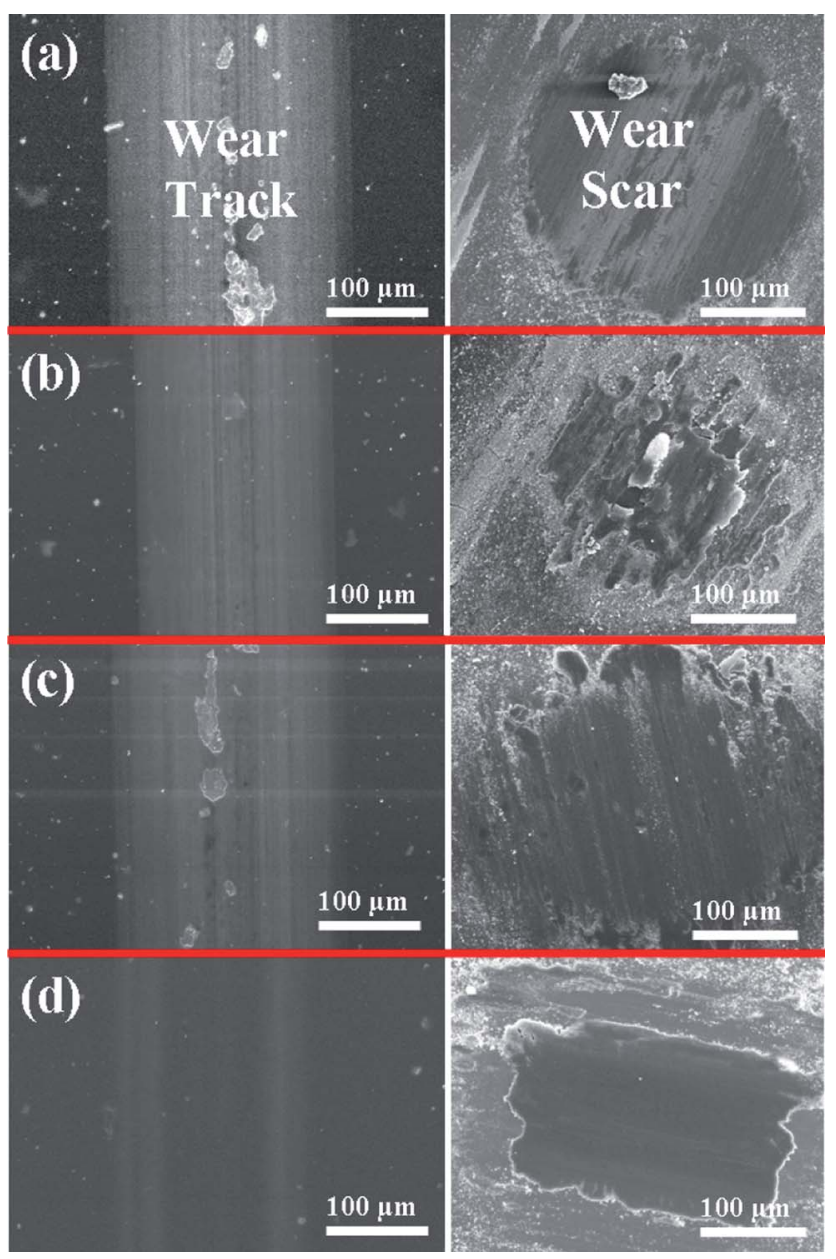

Fig. 6 SEM images of wear tracks and wear scars for as-fabricated: (a) a-C, (b) a-C(Al), (c) nc-WC/a-C and (d) nc-WC/a-C(Al) coatings under dry friction.
nc-WC/a-C(Al) carbon-based nanocomposite coating, it shows that the wear mark is almost entirely covered with the continuous and compacted transferred film. Furthermore, the wear tracks for the as-fabricated a-C, a-C(Al), nc-WC/a-C and nc-WC/a-C(Al) carbon-based coatings under dry friction are characterized by XPS, as shown in Fig. 7. It is found that the XPS C1s spectra of the wear tracks and their as-deposited coatings present very small difference for the a-C and nc-WC/a$\mathrm{C}$ coatings. However, the peak intensities of the XPS $\mathrm{C} 1 \mathrm{~s}$ spectra of the wear tracks for the a-C(Al) and nc-WC/a-C(Al) coatings is obviously augmented compared to their corresponding as-deposited coatings, indicating that the $\mathrm{WC}$ and $\mathrm{Al}$ content are relatively little whereas the $\mathrm{C}$ content is comparatively large on the surface of the wear tracks. These results can prove that the graphitization on the frictional contact surfaces for the a-C(Al) and nc-WC/a-C(Al) coatings is relatively high, reflecting that the doping with $\mathrm{Al}$ has a potential to promote the graphitization of the as-fabricated carbon-based coatings under sliding friction conditions. Graphitization induced by localized rising temperature at the asperity contacts can form a low shear strength graphitic interlayer (transfer layer) between the ball and the coating, which plays a very important role for the coating to reduce the friction and wear. ${ }^{39}$ Considering the above characteristic of wear tracks and wear scars, superior tribological properties for the nc-WC/a-C(Al) nanocomposite carbon-based coating should be mainly attributed to the formation of low shear strength graphitic tribofilm on the wear track and the continuous and compacted transferred film on the counter body. Besides, in order to prove the existence of low shear strength graphitic tribofilm on the wear track for the nc-WC/a-C(Al) carbon-based nanocomposite coating, its transverse cross-section of wear track is observed by HRTEM and thereby a sample is prepared by FIB. As shown in Fig. 8, the "dark" surface layer compared to the light layer on the wear track is evidently observed, which shows that the tribofilm with thickness of $\sim 30 \mathrm{~nm}$ is formed on the surface of the wear track for the nc-WC/a-C(Al) carbon-based nanocomposite coating.

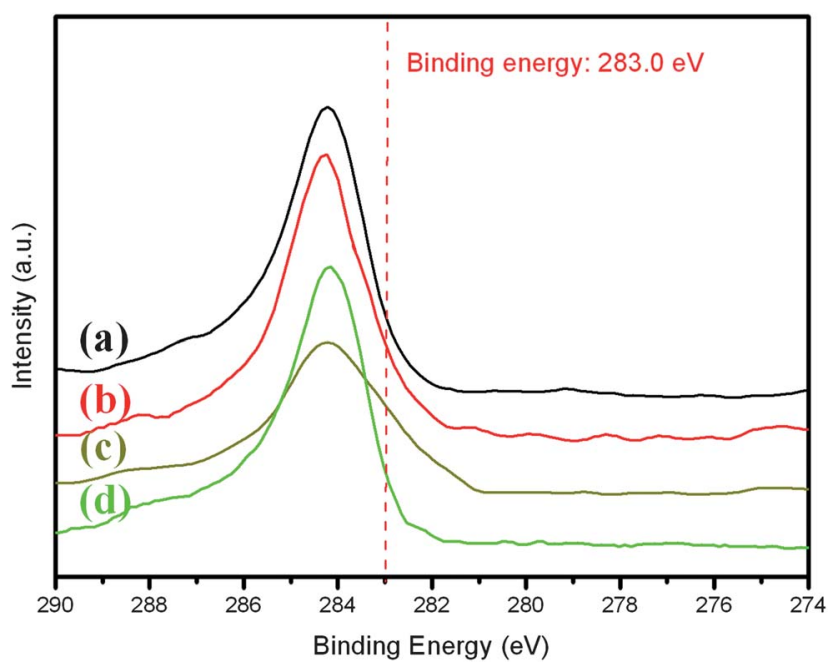

Fig. 7 XPS C1s spectra of wear tracks for as-fabricated: (a) a-C, (b) a$\mathrm{C}(\mathrm{Al})$, (c) nc-WC/a-C and (d) nc-WC/a-C(Al) coatings under dry friction. 


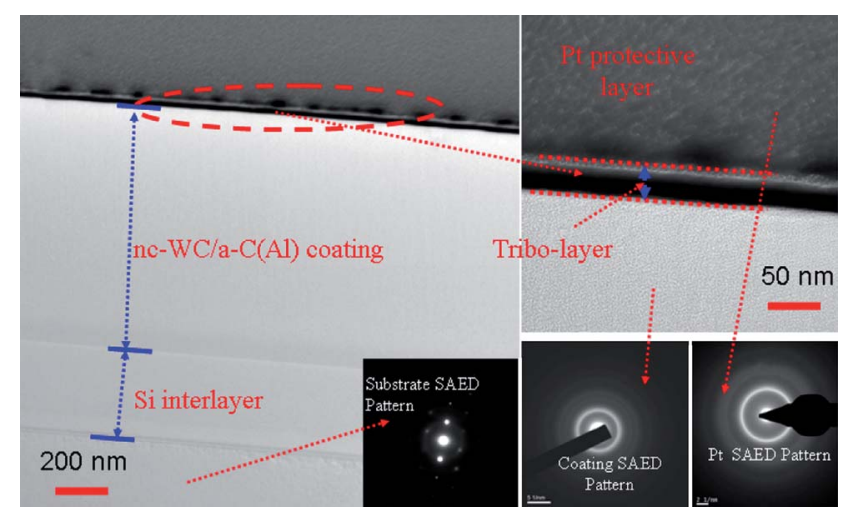

Fig. 8 TEM cross-section images of tribofilm formed on the surface of wear track for nc-WC/a-C(Al) carbon-based coating.

\subsection{Synergic mechanism by the microstructure and phase segregation}

As analyzed in the above mechanical and tribological properties, it is demonstrated that doping with $\mathrm{W}$ can construct a nanocrystallite/amorphous microstructure and thereby increase the hardness whereas it has a small contribution in the reduction of internal stress, friction and wear of the coating. Meanwhile, it is demonstrated that doping with $\mathrm{Al}$ has a great contribution in the reduction of internal stress and friction of the coating but at certain expense of the hardness. Particularly, the wear tracks and scars on the counter body characterized by SEM and XPS confirm that graphitization on the frictional contact surfaces easily occurs by doping with $\mathrm{Al}$ whereas the graphitization is not pronounced by doping with $\mathrm{W}$. Therefore, it can be deduced that doping with $\mathrm{Al}$ has a great potential to promote phase segregation of graphitic carbon from the as-fabricated carbon-based coatings under sliding friction conditions. As a result, the $\mathrm{W}$ and Al co-doped nc-WC/a-C(Al) carbon-based nanocomposite coating can achieve a superior combination of mechanical properties with low internal stress and high adhesion strength as well as keeping high hardness. At the same time, this nc-WC/a$\mathrm{C}(\mathrm{Al})$ coating can easily form a low shear strength graphitic tribofilm on the surface of the wear track and a continuous and compacted transferred film on the counter body, and thereby it results in low friction and high anti-wear properties compared to a-C, a-C(Al) and nc-WC/a-C carbon-based coatings.

The effects of $\mathrm{W}$ and $\mathrm{Al}$ metals in the a-C matrix are further confirmed by theoretical calculations using density functional theory (DFT). DFT calculations using Ultrasoft Pseudopotentials are performed using the CASTEP program which is based on the plane-wave pseudopotential method. ${ }^{43}$ The generalized gradient approximation (GGA) is used for the electron exchange-correlation function and we have used a plane wave energy cut-off of $500 \mathrm{eV}$. The calculations are carried out using super cells containing 8 atoms. In this case, we suppose that the a-C coating is idealistically composed of $\mathrm{sp}^{3}-\mathrm{C}$ and it is denominated as a $\mathrm{C}_{8}\left(\mathrm{sp}^{3}\right.$-carbon) system. By the above experimental result, $\mathrm{Al}$ is uniformly doped into the a-C matrix, so $\mathrm{Al}$ is substituted into the partial $\mathrm{C}$ sites of the $\mathrm{C}_{8}\left(\mathrm{sp}^{3}\right.$-carbon) system to become an $\mathrm{Al}_{1} \mathrm{C}_{7}\left(\mathrm{sp}^{3}\right.$-carbon) system by considering the $\mathrm{Al}$ content. Because the doping of $\mathrm{W}$ forms cubic $\mathrm{WC}_{1-X}$ nanocrystallites in the a-C matrix, so we use the cubic $\mathrm{WC}_{1-X}$ super cell, i.e. the $\mathrm{W}_{4} \mathrm{C}_{4}$ system, to investigate the relationship between $\mathrm{W}$ and $\mathrm{C}$. Subsequently, the formation energy for the release of one graphitic $\left(\mathrm{sp}^{2}-\mathrm{C}\right)$ carbon is calculated by evaluating the energy difference in the $\mathrm{C}_{8}\left(\mathrm{sp}^{3}\right.$-carbon), $\mathrm{W}_{4} \mathrm{C}_{4}$ and $\mathrm{Al}_{1} \mathrm{C}_{7}\left(\mathrm{sp}^{3}\right.$ carbon) system, respectively, shown as follows:

$$
\begin{gathered}
\Delta E(\text { no-doping })=E\left(\mathrm{C}_{7}\left(\mathrm{sp}^{3} \text {-carbon }\right)\right)+E\left(\mathrm{C}_{1}\left(\mathrm{sp}^{2} \text {-carbon }\right)\right)- \\
E\left(\mathrm{C}_{8}\left(\mathrm{sp}^{3} \text {-carbon }\right)\right), \Delta E=-1.126 \mathrm{eV}
\end{gathered}
$$

$$
\begin{aligned}
& \Delta E(\mathrm{~W} \text {-doping })=E\left(\mathrm{~W}_{4} \mathrm{C}_{3}\right)+E\left(\mathrm{C}_{1}\left(\mathrm{sp}^{2} \text {-carbon }\right)\right)-E\left(\mathrm{~W}_{4} \mathrm{C}_{4}\right), \\
& \Delta E=-1.107 \mathrm{eV}
\end{aligned}
$$

$\Delta E(\mathrm{Al}$-doping $)=E\left(\mathrm{Al}_{1} \mathrm{C}_{6}\left(\mathrm{sp}^{3}\right.\right.$-carbon $\left.)\right)+E\left(\mathrm{C}_{1}\left(\mathrm{sp}^{2}\right.\right.$-carbon $\left.)\right)-$ $E\left(\mathrm{Al}_{1} \mathrm{C}_{7}\left(\mathrm{sp}^{3}\right.\right.$-carbon $\left.)\right), \Delta E=-3.960 \mathrm{eV}$

Comparing with the formation energy for the release of one graphitic $\left(\mathrm{sp}^{2}-\mathrm{C}\right)$ carbon in the no-doping a-C system, it can be seen that the formation energy decreases in the $\mathrm{W}_{4} \mathrm{C}_{4}$ system while it increases largely in the $\mathrm{Al}_{1} \mathrm{C}_{7}\left(\mathrm{sp}^{3}\right.$-carbon) system. This demonstrates that $\mathrm{Al}$ doping can result in a strong thermodynamic driving force to release graphitic carbon from the a-C structure while $\mathrm{W}$ doping has no effect of releasing graphitic carbon. These are very consistent with the above experimental results of friction and wear of the as-fabricated coatings. The effect is mainly attributed to the close lying carbon atoms not forming strong bonds with the $\mathrm{Al}$ atom, i.e. the $\mathrm{Al}$ atoms do not form pronounced bonds with any of their nearest neighbors. However, the $\mathrm{W}$ atoms form strong bonds with the $\mathrm{C}$ atoms to be WC nanocrytallites. The density of states (DOS) of the $\mathrm{W}_{4} \mathrm{C}_{4}$ and $\mathrm{Al}_{1} \mathrm{C}_{7}\left(\mathrm{sp}^{3}\right.$-carbon) system are shown in Fig. 9, and they confirm that $\mathrm{W}$ and $\mathrm{C}$ form strong bonds while $\mathrm{Al}$ and $\mathrm{C}$ almost form no bonds. The calculated electron density for the (100) plane of the WC system shown in Fig. 9a also presents highly directional bonds between the $\mathrm{W}$ and $\mathrm{C}$ atoms due to electron accumulation between the two atomic sites. However, there is no electron accumulation at the $\mathrm{Al}$ sites; in fact, the $\mathrm{Al}$ electron is almost smeared out over the whole $\mathrm{Al}_{1} \mathrm{C}_{7}$ system, which is very consistent with the information given by the DOS, revealing that weak or almost no interaction occurs between the $\mathrm{Al}$ and $\mathrm{C}$ atoms. The above theoretical calculations support the experimental results that the doping of $\mathrm{Al}$ metal has a great potential to promote phase segregation of graphitic carbon from the as-fabricated carbon-based coatings under sliding friction conditions due to a largely increased thermodynamic driving force whilst it also contributes to improving some mechanical properties. Whereas the effect of doping with $\mathrm{W}$ metal is mainly to restore the hardness and thereby improve the load support capability due to the WC nanocrystalline enhancement effects in the nanocrystallite/amorphous structure. Thus, the co-incorporation of strong-carbide-forming $\mathrm{W}$ metal and weak-carbide-forming $\mathrm{Al}$ in the a-C matrix not only contributes to constructing a nanocrystallite/amorphous structure but also creates a situation of phase segregation of the graphitic carbon.

Besides, the finite element method is used to simulate the stress distribution in the nc-WC/a-C(Al) carbon-based nanocomposite coating under the test conditions using ANSYS MULTIPHYSICS software (ANSYS v8.2 ANSYS, Inc.). ${ }^{44}$ Due to high material hardness, the counter body, coating and substrate are all modeled to behave in a linear-elastic manner under the tested 

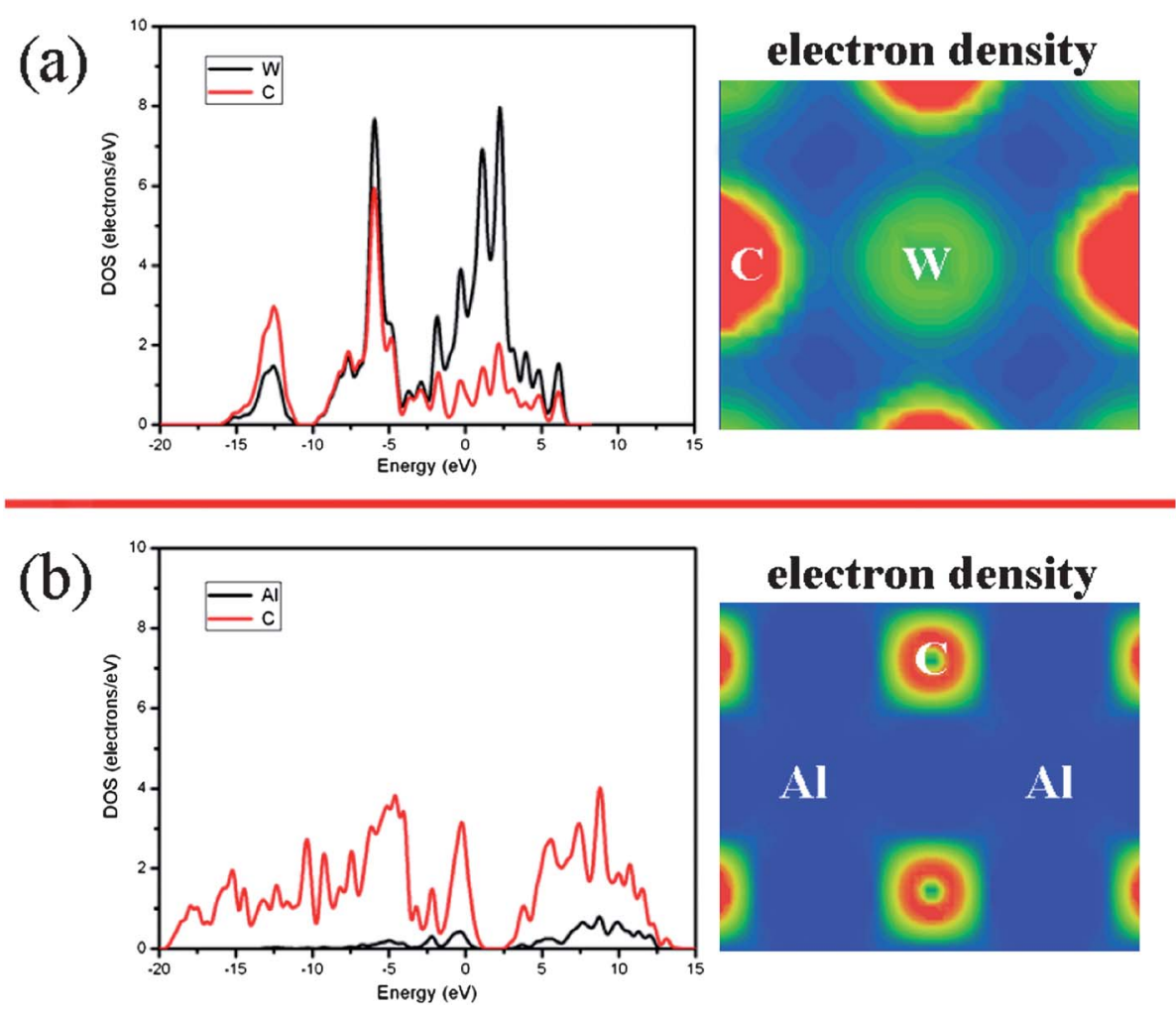

Fig. 9 The density of states (DOS) and electron density ((100) plane): (a) carbide WC and (b) $\mathrm{Al}_{1} \mathrm{C}_{7}$ system.

load of $5 \mathrm{~N}$. The following parameters are used in the calculations of the stress distribution:

- Counter body.

Radius of spherical counter body: $2.5 \mathrm{~mm}$.

Material: stainless steel.

Young's modulus: $200 \mathrm{GPa}$.

Poisson's ratio: 0.3 .

Roughness: ideally smooth.

- Coating.

Thickness: $2.1 \mu \mathrm{m}$.

Material: nc-WC/a-C(Al) coating.

Young's modulus: 213.2 GPa.

Poisson's ratio: 0.22 .

Roughness: ideally smooth.

- Substrate.

Geometry: ideally smooth plate.

Material: silicon $\mathrm{p}(100)$.

Young's modulus: $130 \mathrm{GPa}$.

Poisson's ratio: 0.278 .

Since the load support is mainly related to the compressive stress, only the distribution of compressive stress is plotted. As shown in Fig. 10, under the applied normal load of $5 \mathrm{~N}$, the highest compressive stress mainly distributes in the whole crosssection of the nc-WC/a-C(Al) coating and extends to the substrate, indicating that a $5 \mathrm{~N}$ normal load is supported by the whole nc-WC/a-C(Al) coating and substrate. In the above analyses of the TEM cross-sections of wear track for the nc-WC/ a-C(Al) coating, we found that the tribofilm on the surface of the wear track is just of about $30 \mathrm{~nm}$ thickness. Therefore, it can be concluded that this very thin and soft tribofilm does not cause the sacrifice of the load support capability of the nc-WC/a-C(Al) coating.

Subsequently, the friction process is illustrated in Fig. 11 to reveal the mechanism of achieving superior friction and wear behaviors for the nc-WC/a-C(Al) coating during the sliding friction. Generally, the friction force is proportional to the contact area $A$ and shearing strength $S: F=A S$. The friction coefficient $\mu$ is defined as the friction force $F$ divided by the normal load $N: \mu=A S / N$. Hardness is defined as $H=N / A$. So, $\mu=S / H$. This means the friction coefficient $\mu$ is approximately proportional to the ratio of the shearing strength $S$ to the

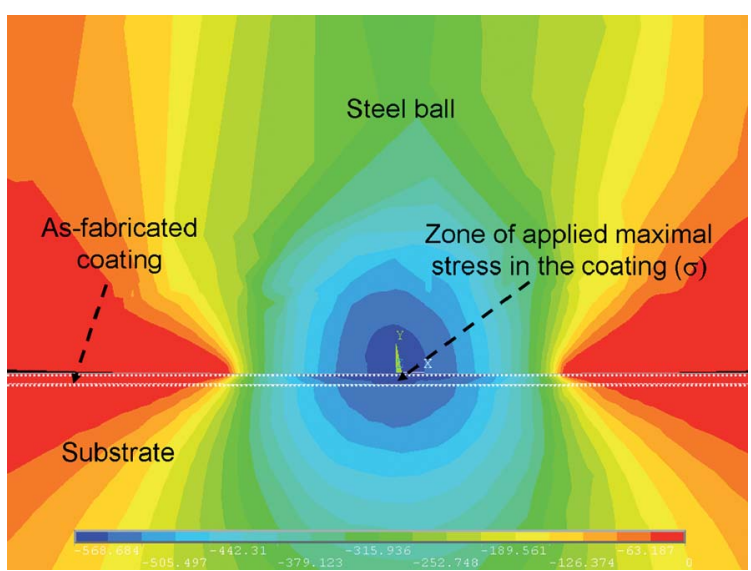

Fig. 10 Finite elements simulation of stress distribution in the nc-WC/a$\mathrm{C}(\mathrm{Al})$ carbon-based coating by applied normal load of $5 \mathrm{~N}$. 


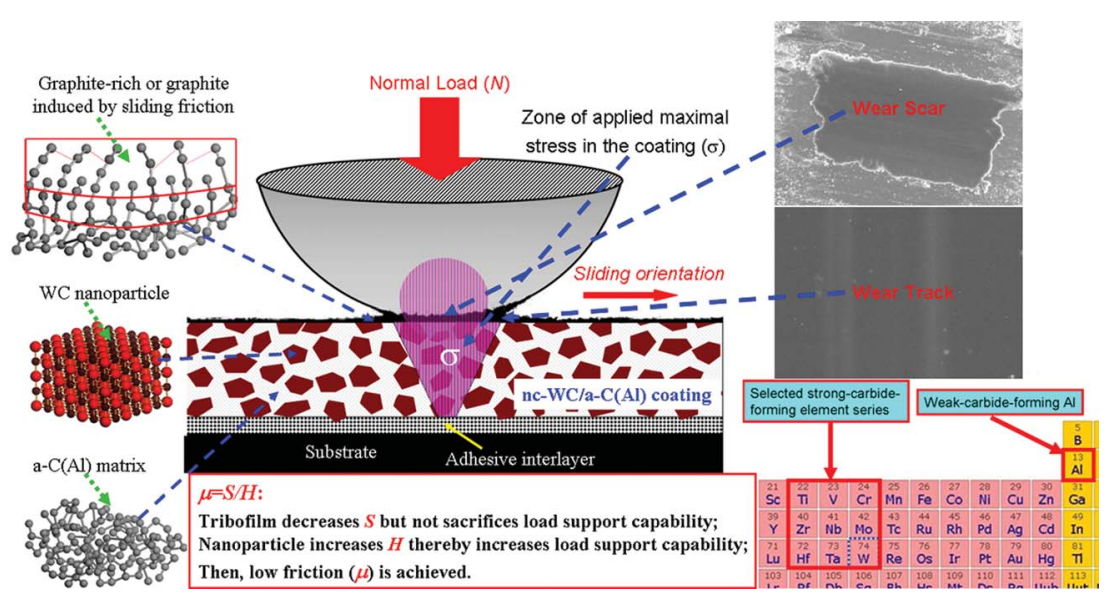

Fig. 11 Schematic diagram of frictional mechanism for the nc-WC/a-C(Al) carbon-based coating.

hardness $H$ of the supporting coating. To develop novel low friction and anti-wear solid lubrication coatings, the hardness $H$ of the deposited coatings should be increased and the shearing strength $S$ on the contact surface should be decreased. As discussed in the above section, the reduction in the friction coefficient of the nc-WC/a-C(Al) coatings can be directly attributed to the formation of a carbon-rich tribofilm where contact surface graphitization plays an important role. Also, the theoretical calculations prove that the weak-carbide-forming $\mathrm{Al}$ incorporated in the a-C coating has a great potential to favor an increased phase segregation of graphitic carbon at elevated temperatures induced by sliding friction due to the strong thermodynamic driving force. For the nc-WC/a-C(Al) carbon-based nanocomposite coating, the formation of a graphitic interlayer (tribofilm) on the contact surface provides a low shearing strength $S$. Meanwhile, the WC nanoparticles enhancement effects provide relatively high hardness $H$ and thereby increase the load support capability of the coating. Particularly, the tribofilm just $\sim 30 \mathrm{~nm}$ thickness formed on the surface of the wear track does not cause a sacrifice in the load support capability because the finite elements simulation reveals that the stress mainly distributes over the whole cross-section in the coating when applying a $5 \mathrm{~N}$ normal load. By the contributions of the above factors, the nc-WC/a-C(Al) carbon-based nanocomposite coating can achieve low friction and high wear-resistance properties compared to the a-C, a-C(Al) and nc-WC/a-C carbonbased coatings.

\subsection{Achieving a series of novel low friction carbon-based nanocomposite coatings}

Remarkably, the model of SCF W and WCF Al to construct this novel nc-WC/a-C(Al) carbon-based nanocomposite coating might be employed to fabricate a series of carbon-based nanocomposite coatings. In the periodic table of the elements the strong-carbide-forming (SCF) metals also include $\mathrm{Ti}, \mathrm{V}, \mathrm{Cr}, \mathrm{Zr}$, $\mathrm{Nb}$, Mo, Hf and $\mathrm{Ta}$ elements. According to the theoretical calculations, we predict that one of these strong-carbide-forming $\mathrm{Ti}, \mathrm{V}, \mathrm{Cr}, \mathrm{Zr}, \mathrm{Nb}, \mathrm{Mo}$, Hf or Ta metals combining with weakcarbide-forming (WCF) metal Al can be used to fabricate carbon-based nanocomposite coatings, which might also have superior mechanical and tribological properties similar to that of the above nc-WC/a-C(Al) carbon-based nanocomposite coating. The chemical compositions of as-fabricated carbon-based nanocomposite coatings including nc-TiC/a-C(Al), nc-VC/a$\mathrm{C}(\mathrm{Al})$, nc-CrC/a-C(Al), nc-ZrC/a-C(Al), nc-NbC/a-C(Al), nc$\mathrm{MoC} / \mathrm{a}-\mathrm{C}(\mathrm{Al})$, nc-HfC/a-C(Al) and nc-TaC/a-C(Al) coatings are listed in Table 3. Besides, the microstructure of these carbonbased nanocomposite coatings was characterized by TEM. HRTEM images (Fig. 12a-h) reveal that these eight kinds of asfabricated coatings possess a typical nanocomposite/amorphous microstructure where the carbide nanoparticles (which mostly are fringed) are uniformly formed in the amorphous carbon matrix. The SAED patterns, which display sharp rings with calculated lattice spacings, prove that the nanocrystallites are the $\mathrm{Ti}, \mathrm{V}, \mathrm{Cr}, \mathrm{Zr}, \mathrm{Nb}, \mathrm{Mo}$, Hf and Ta carbide. Similar to the nc-WC/ a-C(Al) carbon-based nanocomposite coating, the weak-carbideforming $\mathrm{Al}$ also dissolves into the a-C matrix according to the XPS C1s and Al2p analyses. Also, the XRD results further confirm the typical nanocomposite/amorphous microstructure for these carbon-based coatings, as shown in Fig. 13.

In order to prove these as-fabricated nc-TiC/a-C(Al), nc-VC/a$\mathrm{C}(\mathrm{Al}), \quad$ nc-CrC/a-C(Al), nc-ZrC/a-C(Al), nc-NbC/a-C(Al), nc-MoC/a-C(Al), nc-HfC/a-C(Al) and nc-TaC/a-C(Al) carbonbased nanocomposite coatings also have superior friction and wear behaviors, the ball-on-disk tribometer is used to systematically evaluate these carbon-based nanocomposite coatings. The parameters are kept the same with that of the above nc-WC/a$\mathrm{C}(\mathrm{Al})$ carbon-based nanocomposite coating, and are listed as follows: normal load of $5 \mathrm{~N}$, reciprocating amplitude of $5 \mathrm{~mm}$, reciprocating frequency of $5 \mathrm{~Hz}$ (line speed of $0.05 \mathrm{~m} \mathrm{~s}^{-1}$ ) and test time of $60 \mathrm{~min}$ (cycles of 18000 ). Fig. 14 shows the friction coefficient and wear rate of these as-fabricated nc-TiC/a-C(Al), nc-VC/a-C(Al), nc-CrC/a-C(Al), nc-ZrC/a-C(Al), nc-NbC/a$\mathrm{C}(\mathrm{Al})$, nc-MoC/a-C(Al), nc-HfC/a-C(Al) and nc-TaC/a-C(Al) carbon-based nanocomposite coatings. It can be seen that all these coatings present a very low friction coefficient of about 0.05-0.06 and high anti-wear capability similar to that of the above nc-WC/a-C(Al) coating, and their wear rates stay between $8.4 \times 10^{-17} \mathrm{~m}^{3} \mathrm{~N}^{-1} \mathrm{~m}$ and $3.7 \times 10^{-16} \mathrm{~m}^{3} \mathrm{~N}^{-1} \mathrm{~m}$. Considering their friction and wear results, it can be concluded that the SCF $\mathrm{Ti}, \mathrm{V}, \mathrm{Cr}, \mathrm{Zr}, \mathrm{Nb}, \mathrm{Mo}$, Hf or Ta metal combining with the WCF 
Table 3 Chemical composition of a series of as-fabricated carbon-based coatings

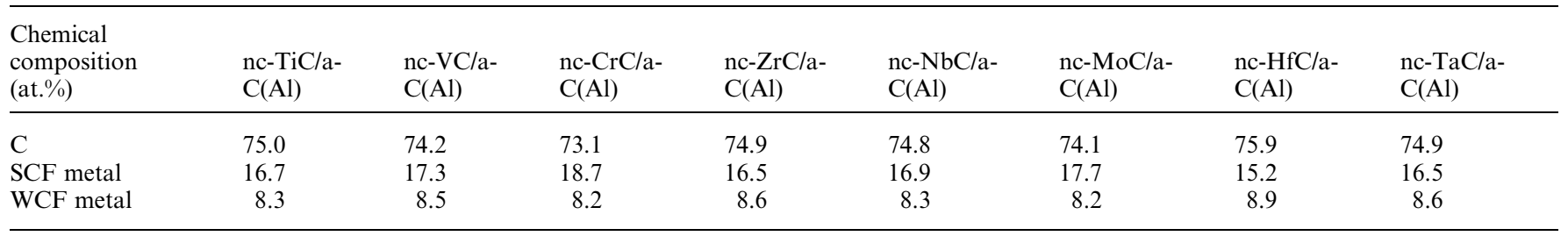
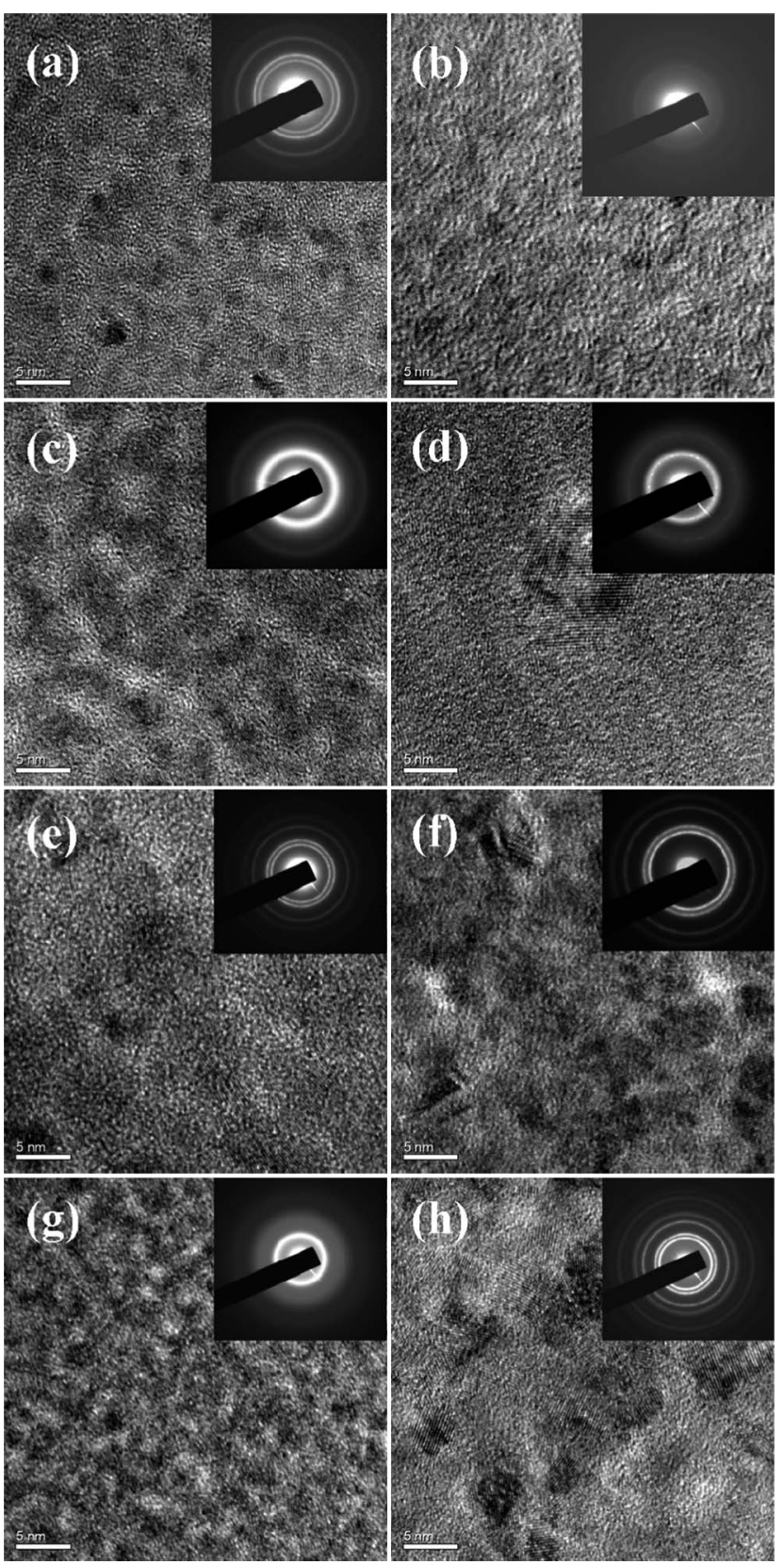

Fig. 12 HRTEM bright-field images and SAED pattern for as-fabricated carbon-based nanocomposite coatings: (a) nc-TiC/a-C(Al), (b) nc$\mathrm{VC} / \mathrm{a}-\mathrm{C}(\mathrm{Al})$, (c) nc-CrC/a-C(Al), (d) nc-ZrC/a-C(Al), (e) nc-NbC/a$\mathrm{C}(\mathrm{Al})$, (f) nc-MoC/a-C(Al), (g) nc-HfC/a-C(Al) and (h) nc-TaC/a-C(Al).

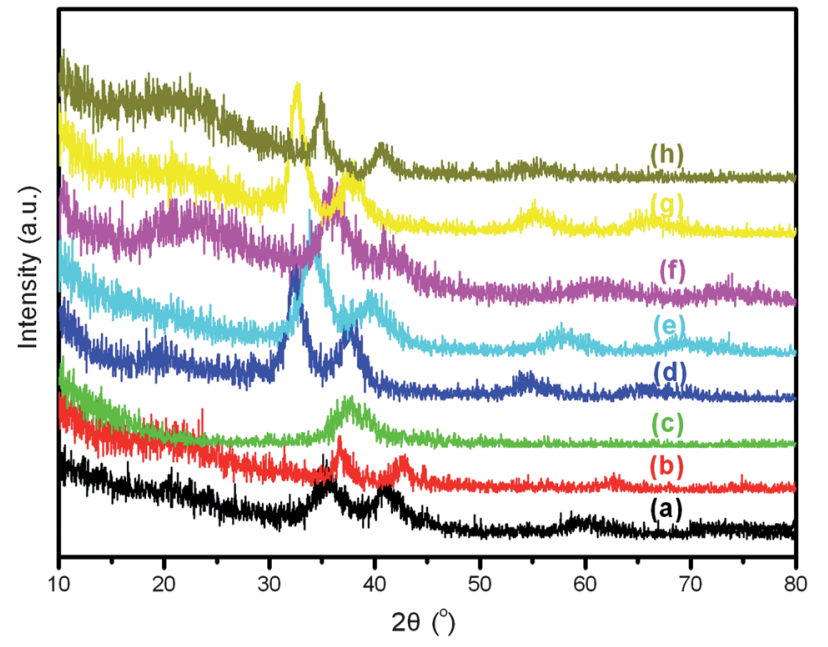

Fig. 13 XRD spectra of as-fabricated carbon-based nanocomposite coatings: (a) nc-TiCla-C(Al), (b) nc-VC/a-C(Al), (c) nc-CrC/a-C(Al), (d) nc-ZrCla-C(Al), (e) nc-NbC/a-C(Al), (f) nc-MoC/a-C(Al), (g) nc-HfC/a$\mathrm{C}(\mathrm{Al})$ and $(\mathrm{h})$ nc-TaCla-C(Al).

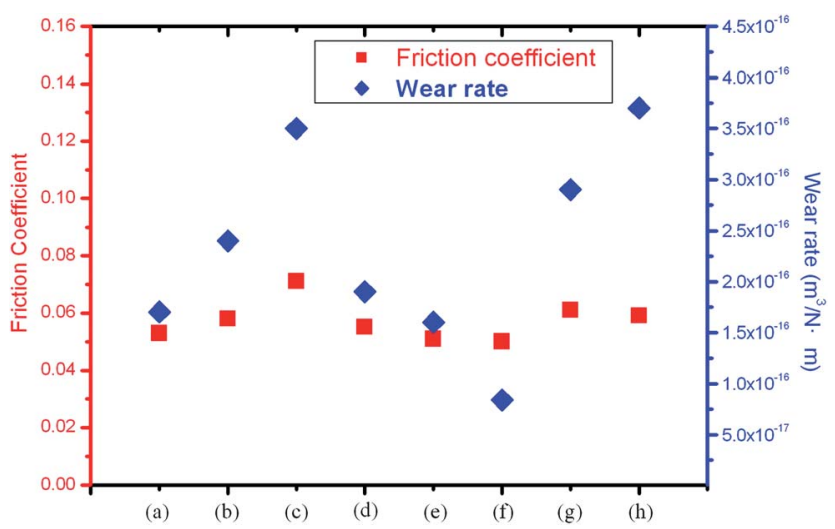

Fig. 14 Friction coefficient and wear rate of as-fabricated nanocomposite coatings: (a) nc-TiC/a-C(Al), (b) nc-VC/a-C(Al), (c) nc-CrC/a$\mathrm{C}(\mathrm{Al})$, (d) nc-ZrCla-C(Al), (e) nc-NbCla-C(Al), (f) nc-MoC/a-C(Al), (g) nc-HfC/a-C(Al) and (h) nc-TaC/a-C(Al) under dry friction.

Al metal can be used to fabricate carbon-based nanocomposite coatings, which also achieve superior tribological properties. Consequently, we successfully achieve a series of novel carbonbased nanocomposite coatings with low-friction and anti-wear performances via constructing a nanocrystallite/amorphous microstructure and creating a strong thermodynamic driving force to promote phase segregation of graphitic carbon by coincorporating the SCF metal and WCF metal into the a-C 
matrix, and these coatings might be good substitute candidates for solid lubricating coatings in engineering applications.

\section{Conclusions}

Novel low friction carbon-based nanocomposite coatings are successfully fabricated on silicon wafer substrates using a magnetron sputtering process. Superior mechanical and tribological properties of the as-fabricated coatings are achieved by tailoring the microstructure and phase segregation synergies. The most important results could be summarized as follows:

(1) The strong-carbide forming $\mathrm{W}$ metal can restore the hardness so as to increase the load support capability by the carbide nanocrystalline enhancement effects in the nanocrystallite/amorphous microstructure.

(2) The weak-carbide forming $\mathrm{Al}$ metal can drastically diminish the magnitude of internal stress and improve the adhesion strength. Also, it promotes the segregation of graphitic carbon from the a-C structure so as to form a low shear strength graphitic tribo-layer on the friction contact surface.

(3) The novel nc-WC/a-C(Al) carbon-based nanocomposite coating achieves the lowest friction coefficient $(\sim 0.05)$ and specific wear rate $\left(\sim 1.8 \times 10^{-16} \mathrm{~m}^{3} \mathrm{~N}^{-1} \mathrm{~m}\right)$ compared to the a-C, a-C(Al), nc-WC/a-C carbon-based coatings. The significant improvements in tribological performances of the nc-WC/a$\mathrm{C}(\mathrm{Al})$ coating are mainly attributed to synergic contributions of the nanocrystallite/amorphous microstructure and correlative graphitization induced by sliding friction.

(4) The approach to construct this novel nc-WC/a-C(Al) carbon-based nanocomposite coating by tailoring the microstructure and phase segregation synergies via co-incorporation of SCF W and WCF Al was successfully employed to fabricate a wide class of carbon-based nanocomposite coatings coupled with low friction and high wear-resistance properties.

\section{Acknowledgements}

The authors are grateful for financial support from the National Natural Science Foundation of China (Grant no. 50905178 \& no.11172300). The authors gratefully acknowledge Mr Yaonan Zhang and Guohui Zhao for supporting the numerical simulation at Lanzhou branch of supercomputing CAS.

\section{References}

1 R. Hauert, J. Patscheider, L. Knoblauch and M. Diserens, $A d v$. Mater., 1999, 11, 175.

2 G. Cherkashinina and O. Ambacher, Appl. Phys. Lett., 2006, 88, 172114.

3 Q. Luo, S. Wang, Z. Zhou and L. Chen, J. Mater. Chem., 2011, 21, 9746.

4 A. Grill, Surf. Coat. Technol., 1997, 94-95, 507.
5 H.-S. Zhang and K. Komvopoulos, J. Appl. Phys., 2009, 105, 083305. 6 A. Anttila, R. Lappalainen, V. Tiainen and M. Hakovirta, $A d v$. Mater., 1997, 9, 1161.

7 Tribology of Diamond-Like Carbon Films: Fundamentals and Applications, ed. C. Donnet and A. Erdemir, Springer, New York, 2008 , p. 311.

8 A. Erdemir and C. Donnet, J. Phys. D: Appl. Phys., 2006, 39, 311.

9 O. L. Eryilmaz and A. Erdemir, Wear, 2008, 265, 244.

10 A. Erdemir, O. L. Eryilmaz and G. Fenske, J. Vac. Sci. Technol., A, 2000, 18, 1987.

11 D. Sheeja, B. Tay, S. Lau and X. Shi, Wear, 2001, 249, 433.

12 D. McKenzie, Y. Yin, N. Marks, C. Davis, B. Pailthorpe, G. Amaratunga and V. Veerasamy, Diamond Relat. Mater., 1994, 3, 353.

13 T. Scharf, M. Romanes, K. Mahdak, J. Hwang, R. Banerjee, R. Evans and G. Doll, J. Appl. Phys., 2008, 93, 151909.

14 A. Voevodin and J. S. Zabinski, Compos. Sci. Technol., 2005, 65, 741.

15 Y. Pei, P. Huizenga, D. Galvan and J. Hosson, J. Appl. Phys., 2006, 100, 114309

16 Y. Pei, D. Galvan and J. Hosson, Acta Mater., 2005, 53, 4505.

17 Y. Pei, C. Chen, K. Shaha, J. De Hosson, J. Bradley, S. Voronin and M. Cada, Acta Mater., 2008, 56, 696.

18 T. Sonoda, S. Nakao and M. Ikeyama, Vacuum, 2010, 84, 666.

19 K. Baba, R. Hatada and Y. Tanaka, Surf. Coat. Technol., 2007, 201, 8362.

20 S. Huang, M. Ng, M. Samandi and M. Brandt, Wear, 2002, 252, 566.

21 A. Peters and M. Nastasi, Vacuum, 2002, 67, 169.

22 A. Czyzniewski, Thin Solid Films, 2003, 433, 180.

23 C. Silva, J. Branco and A. Cavaleiro, Thin Solid Films, 2006, 515, 1063.

24 J. Veverkova and S. Hainsworth, Wear, 2008, 264, 518.

25 T. Moskalewicz, B. Wendler, S. Zimowski, B. Dubiel and A. CzyrskaFilemonowicz, Surf. Coat. Technol., 2010, 205, 2668.

26 B. Podgornik, S. Jacobson and S. Hogmark, Surf. Coat. Technol., 2005, 191, 357.

27 S. Dub, Y. Pauleau and F. Thiery, Surf. Coat. Technol., 2004, 180181, 551.

28 B. Tay, Y. Cheng, X. Ding, S. Lau, X. Shi, G. F. You and D. Sheeja, Diamond Relat. Mater., 2001, 10, 1082.

29 G. Zhang, P. Yan, P. Wang, Y. Chen and J. Zhang, J. Phys. D: Appl. Phys., 2007, 40, 6748.

30 S. Zhang, X. Bui and Y. Fu, Thin Solid Films, 2004, 467, 261.

31 S. Zhang, X. Bui, X. Zeng and X. Li, Thin Solid Films, 2005, 482, 138 144.

32 O. Wilhelmsson, M. Råsander, M. Carlsson, E. Lewin, B. Sanyal, U. Wiklund, O. Eriksson and U. Jansson, Adv. Funct. Mater., 2007, 17, 1611.

33 S. Zhou, L. Wang and Q. Xue, Tribol. Lett., 2011, 43, 329.

34 S. Zhou, L. Wang and Q. Xue, Surf. Coat. Technol., 2011, 206, 387.

35 A. Leyland and A. Matthews, Surf. Coat. Technol., 2004, 177-178, 317.

36 S. Neuville and A. Matthews, Thin Solid Films, 2007, 515, 6619.

37 S. Neuville, JPJSS, 2009, 3, 33.

38 A. Perry, V. Valvoda and D. Rafaja, Thin Solid Films, 1992, 214, 169.

39 E. Santner, D. Klaffke and G. Köcker, Wear, 1995, 190, 204.

40 Y. Liu, A. Erdemir and E. Meletis, Surf. Coat. Technol., 1996, 82, 48.

41 J. Orwa, I. Andrienko, J. Peng and S. Prawer, J. Appl. Phys., 2004, 96, 6286.

42 V. Singh, J. Jiang and E. Meletis, Thin Solid Films, 2005, 489, 150.

43 S. Clark, M. Segall, C. Pickard, P. Hasnip, M. Probert, K. Refson and M. Payne, Z. Kristallogr., 2005, 220(5-6), 567.

44 K. Holmberg, A. Laukkanen, H. Ronkainen and K. Wallin, Tribol. Int., 2009, 42, 137. 